\title{
Hibridismo y amores como autodefensa: la "Epístola de Amarilis a Belardo" y la afilada respuesta de Lope
}

\author{
J. Ignacio Díez \\ Universidad Complutense \\ igdiez@ucm.es
}

Recepción: 25/02/2021, Aceptación: 06/07/2021, Publicación: 22/12/2021

\begin{abstract}
Resumen
Tras el análisis de algunas cuestiones textuales de una epístola-canción de una supuesta poetisa peruana a Lope de Vega (género y metro en relación con la serie epistolar en Espana, así como la dispositio del poema en la colección de epístolas de Lope en La Filomena), detalladamente se estudia - contra cierto olvido crítico- la muy elaborada respuesta de Lope. La doble proyección biográfica bien organizada más el hibridismo del poema de Amarilis permite insertar ambos textos en un nítido sistema de propaganda personal o de autodefensa. Los distintos factores que se evalúan arrojan muy serias dudas sobre la autoría aceptada del poema de Amarilis.
\end{abstract}

Palabras clave

Epístola; canción; Lope de Vega; hibridismo; autodefensa.

\begin{abstract}
English Title. Hybridism and loves as a self-defence: The "Epistle of Amarilis to Belardo" and Lope's sharp response.

After the analysis of some textual issues of the epistle-canción of a supposed Peruvian poetess to Lope de Vega (gender and meter regarding the epistolary series in Spain, besides the dispositio of the poem in Lope's collection of epistles in La Filomena), Lope's very elaborate response — against a relative critical oblivion —is studied in detail. The double and well-organised biographical projection plus the hybridism of the Amarilis poem allow to insert both texts into a clear system of personal propaganda or of a self-defence. The different factors that are evaluated cast very serious doubts on the accepted authorship of the Amarlis poem.
\end{abstract}

Keywords

Epistle; "canción"; Lope de Vega; hybridism; self-defence. 
A juzgar por las novelas que había en el boudoir de la Sra. Goldsworth, sus intereses intelectuales eran muy amplios, pues iban del Ámbar al Zen (Vladimir Nabokov, Pálido fuego)

y le deleita más lo que le engaña (Lope de Vega, "Belardo a Amarilis")

Mucha atención ha recibido, y más en los últimos tiempos, la extraña epístola de una poetisa peruana, que firma como Amarilis, dirigida a Lope de Vega. La composición poética nos ha llegado en el conjunto epistolar que el Fénix publicó en la miscelánea titulada La Filomena, y va acompañada de la respuesta del poeta español. La inclusión de la misteriosa epístola supone para Lope una buena excusa para un lucimiento de primer orden, pues la epístola mostraría y demostraría que los admiradores del Fénix llegaban hasta el Pacífico; para los hispanoamericanistas o colonialistas es todo un regalo, pues se encuentran con un largo poema que, también aparentemente, ha atravesado un continente y un océano a comienzos del siglo XVII; y para los que afilan las armas en las aristas de las autorías discutidas o improbables puede ser objeto de deseable estudio donde probarlas. El poema, una composición un tanto insólita no solo por la firma y su remoto origen, sino sobre todo por la difícil inserción en un género complejo como es la epístola, se vale de manera híbrida de una forma que es más propia de la canción. ${ }^{1}$

Una de las partes de La Filomena es el valioso conjunto de diez epístolas que siguen a "La Andrómeda". Entre ellas se publican dos epístolas que no son de Lope: una, de Baltasar Elisio de Medinilla, y otra, la famosa "Epístola sexta", que se titula "De Amarilis a Belardo". ${ }^{2}$ La epístola indiana goza de un intencionado misterio por el uso de los sobrenombres pastoriles que encubren al menos a uno de los corresponsales, pues Belardo es claramente Lope de Vega. Los dos poemas, el de Amarilis y el de Lope, son dos epístolas que supuestamente intercambian un hombre y una mujer, caso insólito en la estela epistolar de Horacio. Además Amarilis precisa que escribe desde el Perú y su texto tiene, por tanto, un interés aún mayor al provenir de una pluma de América en una época temprana para la literatura virreinal. ${ }^{3}$

1. Este artículo se encuadra en el Proyecto "Hibridismo y Elogio en la España Áurea" (HELEA PGC2018-095206-B-I00), dirigido por Jesús Ponce Cárdenas y financiado por el Ministerio de Ciencia, Investigación y Universidades y el Fondo Europeo de Desarrollo Regional FEDER.

2. Cito siempre por la edición de Blecua, tanto el texto de Amarilis, como la respuesta de Lope, "Belardo a Amarilis. Epístola séptima" (Obras poéticas, pp. 800-818).

3. "Figura importante por su cultura literaria y personal, esta se desprende en la redacción del poema, mostrando la ingenuidad de quien desea mantenerse bajo incógnito para ofrecer una sublimación del más puro sentimiento al autor lejano”, Becco (1990: 186). También se recoge en la antología de Serna (2004: 317-331). 


\section{La búsqueda de Amarilis}

Sin duda lo que más ha interesado a la crítica es precisamente el verdadero nombre de la poetisa peruana. Los hispanoamericanistas o colonialistas parecen albergar pocas dudas de que la declarada autoría femenina y peruana es cierta, y esa seguridad se orienta decididamente hacia la identificación de Amarilis. Otra cuestión es que sea una tarea fácil, o incluso posible, encontrar a la poetisa que se escondería tras el sobrenombre poético. De modo efectivo se obvia así la sospecha de que se trata de una mixtificación, del propio Lope se ha pensado alguna vez o de alguien próximo. ${ }^{4}$

Frente a los argumentos de quienes cuestionan el origen americano de la epístola se oponen las razones que demostrarían al menos la posibilidad de que una poetisa peruana en los comienzos del siglo XVII haya podido escribir esta larga epístola, e incluso, dando un paso más, se echa mano de los supuestos rasgos específicos de la literatura hispanoamericana o de la literatura de género en la epístola ${ }^{5}$, lo que serviría para cimentar que su autora es una mujer culta, una monja, ${ }^{6}$ que quizá participa en tertulias o academias literarias, que se reafirma como autora muy orgullosamente y muy por encima de la declaración de un amor platónico hacia el gran Lope de Vega. Minimizado o suprimido el problema, no queda más que la inserción de la autora en una cadena que puede llegar hasta el presente. ${ }^{7}$

Es fácil percibir que la presencia de la epístola de "Amarilis a Belardo" es extraña en el bien tejido sistema del corpus epistolar de La Filomena, que per-

4. La partidaria más reciente es Campana (1997: 24): "probablemente algún amigo de Lope, alguien que quizá participó en certámenes poéticos y en la lucha contra sus detractores, que al componer el poema se propuso no solo exaltar al Fénix, sino también apoyarle frente a los críticos, secundarle en su aspiración al amor espiritual y exhortarle a emprender un proyecto literario. Puede que se trate de un poema hecho por encargo del propio Lope, pero es improbable que fuese compuesto por él".

5. La declarada ambición de la segunda parte de Aladro y Ramos-Tremolada (2015: 75) es "demostrar [...] que la Epistola de Amarilis forma parte de la tradición literaria peruana, y no es, como repetidamente se ha sostenido, una mera continuación de las corrientes humanistas europeas de entonces". Vinatea-Recoba (2017) insiste en el criollismo como explicación de las contradicciones de la epístola. En sus conclusiones López Gregoris considera que "más allá del uso correcto y hábil de las referencias clásicas, la lectura o análisis que debe hacerse sobre estos poemas corresponde sobre todo a los estudios de género" (Vinatea-Recoba 2009: 204).

6. "[...] lleva a suponer que no solo se trata de un amor intelectual, sino una pasión reprimida por su condición de monja. Quizá esta es la causa de que escondiera su identidad con un seudónimo", Ortiz Sánchez (2017: 167). También hay otras explicaciones: "Lo más probable es que las autoras hayan ocultado sus nombres, empleando un pseudónimo, como las tapadas limeñas ocultaban sus rostros", Vinatea Recoba (2009: 25).

7. Mayne-Nicholls (2013) considera que Amarilis y Delia Domínguez mantienen un nexo que consiste en que la primera "forma parte de su genealogía como escritora" y que, más que una carta de amor o una reflexión autobiográfica, "el tema de la epístola es posicionarse como autora". Aunque mucho más hábil en sus planteamientos, Holloway (2013) repasa las posiciones críticas pero acepta por la vía de hecho la realidad femenina y "colonial" de Amarilis. 
manece sólidamente unido en un libro misceláneo cuya organización responde a los intereses tanto de un buen conocedor del mercado editorial, como de un poeta que vive de su pluma y que apuesta por elaborar un canon donde insertarse de un modo favorable. De las diez epístolas la de Amarilis destaca por dos características distintivas: está firmada por una mujer o, mejor, está atribuida a un sobrenombre poético-pastoril femenino, y es la única que emplea una métrica ajena al desarrollo de la epístola poética, tradicionalmente llamada "horaciana”, en España. ${ }^{8}$ Esas dos notas, decisivas, pueden levantar dudas sobre la autoría del texto. Que Lope utilice el poema no tanto como, según parecería a primera vista, exhibición narcisista de un gran ego cuya fama alcanza tierras remotas e incluso enamora platónicamente a una diestra poetisa, sino que le sirva de pie forzado para levantar una potente defensa pro vita sua en la respuesta puede resultar más que sospechoso. ${ }^{9} \mathrm{Y}$ aunque no hay una prueba irrefutable de la probable mixtificación, en el balance de lo que es un complejo cóctel hay que agitar también las posibles ironías de los encargos que realiza Amarilis y las respuestas, corteses pero negativas, de Lope, como se verá después.

Tampoco es una prueba definitiva a favor de la autoría femenina y americana que en el resumen biográfico del poema de Amarilis se mencionen hechos de la historia del Perú. Las luchas de los conquistadores y sus herederos, a los que alude el texto, han ocurrido medio siglo antes y no hay referencias a la vida actual en el virreinato, ni siquiera a algo que pueda fecharse desde comienzos del siglo XvII. ${ }^{10}$ Quizá quepa argüir, si la autora es una monja, que no puede aportar datos o referencias de su mundo, siempre que se la imagine enclaustrada. Los rasgos más personales, además de situar la redacción en esas tierras lejanas para el propio Lope y sus lectores, y más allá de ese puñado de alusiones a la historia del territorio, alusiones antiguas como digo, se concretan en los dos abuelos fundadores de una ciudad, en la condición monjil de la autora, en la existencia de una hermana y en la admiración a Lope. Vuelvo después sobre otros detalles.

Hay un acuerdo en fechar la epístola de Lope hacia 1620, a partir del verso 139 ("Marcela con tres lustros ya me obliga"), pues "Marcela, la hija de Lope, nacida en 1605 tenía entonces quince años", ${ }^{11}$ mientras en el poema de Amarilis,

8. Es "un caso excepcional e innovador [... que] ensancha de una manera sorprendente las fronteras de la epístola española”, Rivers (1993-1994: 28; la cursiva es mía). Desde una perspectiva distinta pero complementaria Tauro (1945: 52) había seńalado que se trata de un texto único de la literatura colonial.

9. La epístola también sobresale en un contexto en el que Lope escribe para defenderse y para autoelogiarse, como lo prueba el conjunto epistolar de La Filomena y La Circe, indica Rozas (1983: 469). Pero la respuesta a Amarilis no entra en las cuestiones literarias o en las envidias que a veces estas conllevan, como ocurre en las otras epístolas, sino que es una defensa de su vida, de su comprensión del amor, y lo es porque es una respuesta a la epistola de Amarilis.

10. No hay ningún dato, "por lo menos, que no hubiera podido sacarse de alguna crónica de la conquista del Perú”, Campana (1997: 19).

11. Montesinos (1973: lx, n. 2). 
lógicamente anterior, no hay elemento alguno que permita su datación. ${ }^{12}$ La epístola alude a un par de textos del Fénix, que sí se publican a principios del siglo XviI, La hermosura de Angélica y El peregrino en su patria, de 1602 y 1604 respectivamente, textos conocidos en España y probablemente en Perú. ${ }^{13}$ No hay alusiones a una fama de Lope en América basada en su teatro, como podría suponerse interpretando el amor de oídas de que se vale Amarilis desde el comienzo. Por eso, la posible admiradora, recuerda al Fénix a partir de un poema épico y de una novela de aventuras. ¿ Son lecturas juveniles? Imposible saberlo. ¿No ha podido volver a acercarse a la obra de Lope desde su vida conventual? Es otra posibilidad incomprobable, aunque mostraría la fecha de la epístola, unos quince años anterior a su inclusión en La Filomena y también a la respuesta de Lope, y en todo caso la inactualidad de esas referencias cuando el texto se publica en Madrid.

Resulta como mínimo curiosa la presencia de dos Amarilis en la vida de Lope: una de ellas su amante Marta de Nevares y otra la poetisa peruana. ${ }^{14}$ Pero las coincidencias van sospechosamente mucho más allá, pues "otro dato extraño que no se puede pasar por alto es que los nombres de mujeres citados en la canción (Amarilis, Belisa, Celia, Dorotea) son todos seudónimos de amantes de Lope", ${ }^{15}$ lo que de modo sorprendente suele pasar desapercibido en una crítica como la de Lope que siempre ha sido furibundamente biográfica y que ha llenado buena parte de las aproximaciones a la obra de Lope con la lista de esposas y amantes. ${ }^{16}$

Como decía, el asunto que ha fascinado a la crítica durante muchos años es la posible identificación de Amarilis, a lo que se han consagrado muy diversos trabajos. ${ }^{17}$ Conviene separar en dos el mar Rojo de las aproximaciones entre las

12. Con todo, Vinatea Recoba (2017: 304) fecha la epístola "alrededor de 1615” y remite a Lohmann (1993) (Vinatea Recoba 2009: 127).

13. Ambos tienen distinos elementos en común, como una proyección biográfica muy repartida, en el caso de La hermosura de Angélica a lo largo de miles de versos, Sánchez Jiménez (2018: 148). Una alusión más amplia e inconcreta añade luego Amarilis: "de nadie no recibes, sino cobras / lo que te debe el mundo en prosa y rima" (vv. 275-276).

14. Arellano-Mata (2011: 115-149: "Sacerdote y amante: Marta de Nevares, gran pasión de madurez del Fénix"). Por otro lado la mención, nueve años después de la publicación de La Filomena, de una Amarilis en El laurel de Apolo (II, 167-174), que Lope sitúa en Santa Fe de Bogotá, no resuelve nada.

15. Campana (1997: 21).

16. "No habrá quien le tache de inconstante: diez años le duró el regusto de Elena, quince la plenitud gozosa de Micaela, y luego dieciséis el ensimismamiento y la solicitud hacia doña Marta. El mal estuvo en que concurrieran paralelamente a esas pasiones siete años de cariñosa unión, nunca renunciada, con dońa Isabel, quince atendiendo con más o menos constancia a la achacosa doña Juana y finalmente veintiún años de sacerdocio agitado por remordimientos, desmayos e ímpetus divinos. Y lo peor de todo para su fama es que lo contaba claramente sin celar nada", Goyri (1953: 173-174).

17. Un resumen reciente de las candidatas en Aladro y Ramos-Tremolada (2015: 71-74). En su edición Vinatea Recoba (2009: 26-31) recoge las autoras aducidas y concluye que la auténtica debió estar vinculada por "lazos familiares" con Enrique Garcés, quien tradujo a Petrarca y a Camoens. No he podido consultar la edición de Chang-Rodríguez (2009). Como uno de los posibles 
que prefieren encontrar una poetisa peruana que pueda encajar con las afirmaciones de la epístola y las que rechazan esa vía o dudan de ella para o bien atribuir el poema al propio Lope o a alguien cercano. ${ }^{18}$ Algunas propuestas han envejecido mucho y hoy son inaceptables, pero demuestran a las claras esa pasión de la crítica literaria por buscar the flesh and blood que se puede ocultar en los juegos de los poetas. Es el caso de Asenjo Barbieri, quien en sus Últimos amores de Lope de Vega Carpio, de 1876, sostiene que los versos de la epístola se deben a Marta de Nevares y que fueron retocados después por el poeta. ${ }^{19}$ Millé por su parte indica que "ese personaje fue invención de Lope", ${ }^{20}$ aunque refina más la hipótesis Tauro, que apoyándose en Ricardo Palma recuerda la superchería literaria de una dama limeña que escribía cartas de amor a un crédulo Juan Ramón Jiménez, y el interesante paralelismo apuntaría a una travesura, aunque en lo que atañe a Amarilis lo más importante es que no cree Tauro que la obra sea de Lope pero sí que "parece obra de hombre y huele a mixtificación literaria”. ${ }^{21}$ Algunas identificaciones posibles componen una nada desdeñable lista de nombres en la página web de Huánuco, que informa de que hay un distrito en la ciudad que se llama "Amarilis". ${ }^{22}$

\section{Hibridismos: métrica y género literario}

El estudio de la epístola en verso aún tiene muchas zonas que roturar. Que la principal aproximación, la de Rivers, se hiciera desde el sello de lo clásico, tras una Europa arrasada por la última contienda mundial, es muy comprensible. El prestigio de la vieja cultura, representada además por uno de sus hijos mas reconocidos, el poeta latino Horacio, tiñe con facilidad la recuperación de una buena parte de esa gran tarta, no siempre dulce, que es la epístola poética en España durante el Renacimiento y el Barroco. Sin embargo el "horacianismo" no es una etiqueta de sencillo manejo, dada la complejidad de matices de la producción del poeta latino, ni tampoco la epístola se presta al fácil tratamiento que casi

excesos a los que invita a menudo la búsqueda de la autoría véase la propuesta de Tord que recogen Aladro y Ramos-Tremolada: a partir de los vv. 260-270 encuentra un extrańo acróstico en el que habría que leer "rojo" en un verso y BARAY en los inicios de cada uno de los cinco siguientes. 18. Aladro y Ramos-Tremolada (2015) señalan una "tercera tendencia crítica" para quienes se centran en el estudio del texto y solo incluyen aquí a Sabat (1990) y a las dos editoras modernas: Vinatea Recoba (2009) y Chang-Rodríguez (2009). Creo que habría que contar también y de modo preferente con Campana (1997), por más que cuestione con fuerza (y acierto) que se trate de una autora de Hispanoamérica.

19. Castro-Rennert (1968: 16, n. 9). Tauro precisa que el libro se publicó con el pseudónimo de José Ibero Ribas y Canfranc.

20. Millé y Jiménez (1930: 7).

21. Tauro (1945: 197, n. 171).

22. "Amarilis Huánuco Perú". 
siempre prefiere la pedagogía. Los estudios suelen insistir en las relaciones de epístola y sátira desde sus comienzos, o en la importancia de la amistad masculina y sus modelos, así como en las claras diferencias con la modalidad ovidiana. Sin embargo siguen quedando fuera de la atención crítica otras variedades, ${ }^{23}$ como la epístola cortesana, la que constituye un tratado (que si es horaciana pasa por el contenido literario que hoy se llamaría "teórico") y la octosilábica (que carga con esa supuesta separación insalvable entre la influencia castellana frente a la italiana del endecasílabo y que en la epístola, como en otros géneros, obliga a muchas matizaciones). ${ }^{24}$

No es habitual para un poeta español de los Siglos de Oro recibir desde América una epístola en verso de una admiradora. Tampoco es imposible, como lo probaría el caso de Lope de Vega. Sin embargo, que el poema esté compuesto en una métrica infrecuente podría llevar a pensar en una falta de información sobre un género que cuando Lope publica La Filomena ya tiene casi noventa años de vida en Espańa. Si Garcilaso escribía a Boscán en 1534 desde la tumba de Laura en Avińón, y lo hacía en endecasílabos blancos, ${ }^{25}$ muy pronto Diego Hurtado de Mendoza y el mismo Juan Boscán intercambiarán sendas epístolas que iban a ser, esta vez sí, las creadoras del género en España, que ha venido llamándose epístola horaciana, al menos desde el célebre y fundador trabajo de Elias Rivers (y el necesario complemento de Claudio Guillén) ${ }^{26}$ Desde esos años finales de la década de los treinta en el siglo xvi distintos poetas cultivaron un género tan latino, a veces tan próximo a Horacio y a veces no tanto, que casi al mismo tiempo habían rescatado y con sus peculiaridades los poetas italianos. Aunque solo suelen valorarse algunos hitos, como los tres mencionados y la admirable epístola del capitán Andrés Fernández de Andrada, la producción epistolar es muy extensa. ${ }^{27}$

En el amplio cajón que es la epístola hay textos que tienen una forma más o menos intensa de epistolaridad y que son más bien otra cosa, como el memorial de Quevedo que se titula "Epístola satírica y censoria". ${ }^{28}$ También se da el caso contrario, el de poemas que no son epístolas pero la crítica los ha podido reclamar para la serie, quizá por la mención de un destinatario o por el uso del terceto encadenado o, peor aún, por la necesidad de que todos los poetas (al menos los importantes) hayan tenido que componer una epístola, como ocurriría con

23. La familiar sería una modalidad de la horaciana: "De los dos tipos discernidos por E.P. Morris en las epístolas de Horacio, la "filosófica" (próxima al discurso) y la "familiar" (que simula el diseño de una carta de amigo a amigo), Lope de Vega prefiere el segundo", Sobejano (1993: 25). 24. Díez (2000).

25. Fosalba (2019). Como es sabido, décadas después, Aldana escribirá a su hermano Cosme una epístola en endecasílabos blancos.

26. Rivers (1954); Guillén (1972).

27. Un planteamiento novedoso y amplio sobre la epístola en verso en Marías (2020).

28. Díez (2008). 
Góngora ${ }^{29}$, aunque "estrictamente hablando, este poema [“¡Mal haya el que en señores idolatra"] ya no se puede llamar epístola [...] se ha transformado en un ingenioso soliloquio" ${ }^{30}$ Frente a la producción única (desde Garcilaso), algunos poetas han creado todo un corpus, verdaderamente al estilo horaciano, también muy pronto, como Hurtado de Mendoza ${ }^{31}$ o Cetina, ${ }^{32}$ y en esta línea se inserta claramente Lope de Vega, ${ }^{33}$ que se distancia así en este aspecto y mucho de sus dos "competidores" Góngora y Quevedo.

No se puede hablar de "desviaciones" del canon del terceto como cauce de la epístola, pues comenzarían en el mismo principio de la aclimatación o, mejor, creación del género en España con la epístola de Garcilaso a Boscán y sus diferencias con las de Mendoza y Boscán, las dos que asientan el terceto como la estrofa más utilizada para componer epístolas en verso, horacianas o no. Con todo, el uso de la estancia, habitual en la canción petrarquista, como metro de una epístola resulta insólito. Hay otros ejemplos de variaciones métricas dentro de un canon muy flexible, pues la epístola maneja un puñado de características formales y de contenido que permiten un alto grado de variabilidad en su combinación y también conviene recordar que la "Canción a las ruinas de Itálica", otro texto muy barroco, se vale de estancias para abordar un contenido que ni es amoroso ni petrarquista. Un lector de poesía de los Siglos de Oro sabe de la polivalencia de las estrofas y su adaptabilidad, desde el mismo género-estrofa que es el soneto hasta los distintos usos del terceto en la recepción de los géneros neoclásicos, por poner solo dos ejemplos.

Sin embargo, la composición de la "Epístola de Amarilis a Belardo" con dieciocho estancias idénticas métricamente que disponen de dieciocho versos ${ }^{34}$ parece remitir a un juego de poeta experimentado o a un desafío de academia o incluso a una pista para esa posteridad que ha creído ver en la canción-epístola una mixtificación. Y desde luego resulta extraño componer una epístola en estancias bien entrado el siglo XVII y en medio de otras nueve epístolas que en $L a$ Filomena respetan escrupulosamente la forma del terceto, bien consolidada entonces y no solo en la pluma de Lope de Vega. ¿Se trataría de una excepción con la que se pretende marcar el género de la autora del poema o con la que se quie-

29. Sánchez Robayna (1993).

30. Rivers (1993-1994: 25).

31. Díez (2002b).

32. Ponce Cárdenas (2002).

33. "Sean 20 o 21 las epístolas numerables en la producción de Lope, es indudable su fecundidad en este género, en el cual creo halló uno de los moldes más propicios a la expresión de su persona, su historia y su destino”, Sobejano (1993: 21). Rozas (1983: 470) defiende que la Égloga a Claudio debería titularse Epistola a Claudio, aunque esté compuesta en liras de seis versos, "una de las estrofas del horacianismo español". Justifica Rozas de manera muy convincente que en este poema el estilo sea elevado y no medio o familiar.

34. El poema consta de dieciocho estancias más once versos del commiato (característico de una canción), lo que supone un total de 335 versos. 
re subrayar la lejanía de su origen con respecto a la metrópoli, la gran distancia que hay entre Perú y Madrid? Así lo creen Sabat ${ }^{35}$ y sus seguidores. ¿Es quizá un accidente, una mala comprensión de la historia de la epístola en verso y de su molde estrófico preferido? Parece muy improbable. ¿Es una decidida elección para manifestar el carácter amoroso propio de la canción petrarquista? Es verdad que no solo tienen forma epistolar las epístolas, como diría Perogrullo, sino que distintas estrofas o géneros pueden adoptar la forma epistolar o contar con rasgos epistolares, incluso un soneto y desde luego una canción pueden tener ese sesgo. Sea o no una epístola o incluso si es una canción, tiene un decidido toque epistolar, como lo muestra, además, su escogido encaje en el centro de las nueve epístolas canónicas que Lope agrupa en La Filomena.

Amarilis parece ignorar ese rico desarrollo de la epístola en verso que tiene en Lope uno de los más conspicuos cultivadores, si bien las dos grandes colecciones epistolares del Fénix se publican después de que supuestamente recibiera la epistola indiana. Desde luego cabe creer que el uso de la estancia podría ser una innovación, una forma de marcar una originalidad americana, peruana o femenina de una poeta que hilvana con extraordinaria soltura sus versos para proclamar muy apropiadamente su amor en una de las estrofas más aptas para ello. Pero también puede aceptarse que el uso de una métrica tan insólita pretenda ser un guiño de complicidad a los lectores de poesía que serían invitados así a entrever que la epistola tiene mucho de mixtura, de broma o de aprovechamiento de un pie forzado para que el Fénix conteste y exhiba su numen poético en algunos asuntos que le vienen especialmente bien. Que Lope conteste con el metro clásico, el terceto, manifiesta una comprensión de la epístola que no se deja arrastrar por las novedades recibidas. Por otro lado, en la colección de diez epístolas de La Filomena la sexta, la "indiana", queda así señalada como una epístola distinta, tanto que no merece que se respete el uso que suele afectar al cruce de composiciones poéticas que desde los trovadores obliga a responder, si no por los mismos consonantes, sí en el mismo metro, como corrobora la experiencia fundante de Mendoza y Boscán. ¿Es una broma el intento de convertir en una epístola insólita la que parece llegar desde Perú con ese perfume exótico que proporcionaría el cambio de metro? ¿Hay otros elementos temáticos que profundicen o corroboren este tono lúdico con el que la epístola puede comunicar algo más que su tenor literal?

Mucho menos interés tiene, en mi opinión, discutir el posible horacianismo de la epístola de Amarilis. Con López Gregoris se puede convenir en que el destinatario aparece tarde y no al comienzo, y se puede convenir también en

35. "Amarilis, poeta, probablemente introdujo innovaciones a su epístola en cuanto al metro porque tenía conciencia de su condición femenina y sabía que las epístolas horacianas utilizadas hasta el momento (en versos sueltos o en terza rima) eran, antes que nada, expresión de la amistad masculina” (Sabat 1990: 464). 
que la estructura carece de digresiones y que, por tanto, es bastante rectilínea, aunque es más difícil discutir el uso de un "lenguaje familiar" porque usa "tú" y no "vos", ${ }^{36}$ pues seguramente "tú" es la forma típica del horacianismo. ${ }^{37}$ Pero, como decía, tiene poco sentido la cuestión, pues aunque sí hay una clara intención de proyección biográfica, el texto es epistolar solo en parte, es una declaración de amor (por peculiar que sea) de una mujer a un hombre y no sigue, quizá porque no lo pretende, los preceptos horacianos ${ }^{38}$ (no hay una reflexión filosófica, no abunda el sentido del humor, etc.). Con el toque epistolar la supuesta autora no quiere que su poema se inserte en la serie horaciana: es otro tipo de epístola de difícil clasificación (ni ovidiana, ni familiar, ni cortesana, etc.), sobre todo por un hibridismo muy obvio y al que Lope le saca mucho partido.

\section{Datos, dudas y contexto de un insólito poema}

Una de las más claras marcas epistolares, también muy horaciana, es la aparición del destinario en los primeros versos. Ese vocativo o esa apelación directa crea el sentido inequívoco de una comunicación epistolar: los versos van dirigidos prima facie a ese receptor individual y nominado, aunque en la poética de la epístola que pasa por la imprenta se busca a muchos más lectores, partícipes también de una comunicación directa. En el poema de Amarilis pesa más en su comienzo el componente de la canción, ${ }^{39}$ con dos estrofas que reflexionan sobre el amor, sobre ese amor limitado que a lo largo del texto predica una Amarilis púdica. Belardo aparece en el verso 38, muy tarde para una epístola convencional y es una prueba más del carácter híbrido del poema. En las epístolas tradicionales la mención del destinario puede servir para señalar las distintas partes en que se organiza el poema y esa repetición sirve al tiempo para mantener la ficción epistolar que recuerde al lector que los versos tienen un primer y privilegiado destinatario y Amarilis lo sabe..$^{40}$

El amor es el marco que justifica la escritura del poema, el amor que dice sentir una emisora que no ha visto nunca al destinatario aunque le ha oído o ha oído cosas sobre él. Por eso, el juego del amor de oídas, tan medieval, debe cohonestarse con la posibilidad de que Amarilis haya oído a Lope en su teatro

36. López Grégoris (2009: 195).

37. Aldana trata de "vos" a su hermano Cosme y de "tú" a Arias Montano, como ya indicara Sabat (1990: 461), "tuteando clásicamente a su distinguido amigo", Rivers (1993-1994: 20).

38. Una enumeración en Díez (2002a).

39. Hay una desvinculación originaria de la epístola sobre la canción: la epístola "no es poesía lírica, en el sentido tradicional, no es hija o sucesora del canto o de la canción”, Guillén (1995: 164).

40. Se menciona a Belardo hasta en ocho ocasiones bien distribuidas, en los versos $38,55,56,91$, $169,253,298$ y 327. 
(aunque no se hace referencia a ninguna composición dramática del Fénix, como he indicado, se mantiene en un tono general sobre los textos de Lope):

$$
\begin{aligned}
& \text { oí, Belardo, tus conceptos bellos, } \\
& \text { tu dulzura y estilo milagroso [...] } \\
& \text { y admirando tu ingenio portentoso [...] } \\
& \text { oí tu voz, Belardo. Mas ¿qué digo? } \\
& \text { (vv. 38-39, } 43 \text { y 55) }
\end{aligned}
$$

Parece que el contacto es por la lectura ("y de las tuyas muchas he leído", v. 219), aunque lo relevante es que se trata de un amor físicamente imposible desde el mismo principio, lo que sirve para levantar una barrera de protección un tanto juguetona en esta amante que busca una conexión espiritual o platónica, garanti-

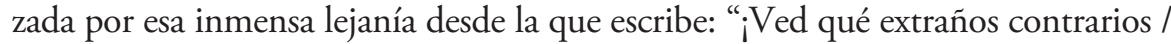
venidos de otro mundo y de otro clima!” (vv. 35-36). Es, con todo, una suerte de amor culpable que solo se mitiga por la calidad del amante (vv. 48-49 y 56), lo que forma un primer elogio del destinatario, en un amor que se ha fraguado a través de la lectura. Como suele resaltarse, el poema quiere hacer creer a su primer destinatario, y a todos los demás que lean el poema impreso, no solo que ha sido compuesto en Perú sino que la autora es una monja (vv. 70-72), con lo que a esa altura de la canción-epístola el lector ha tenido que atravesar setenta versos de justificación de un amor de oídas por un poeta español al que ha leído (y por tanto, oído), pero al que nunca ha visto ni espera (¿ni desea?) ver.

A pesar de todo creo que el verdadero centro del poema no es la expresión de este complejo amor sino la exagerada exaltación de Lope, a través de esta intensa proyección en el Nuevo Mundo, y sin duda por ese motivo el poeta ha publicado la epístola en esa posición central en su colección de epístolas de $\mathrm{La}$ Filomena. Sorprende que una ferviente admiradora solo cite dos obras del Fénix, una en prosa (El peregrino en su patria, con cuyo título se juega en los vv. 91-92, aunque la palabra "peregrino" ya había aparecido en el v. 63), para insistir en consolarse con una especie de peregrino a lo divino, y otra en verso pero también muy narrativa como es La hermosura de Angélica. Las dos se han publicado casi hace veinte ańos cuando la "Epístola de Amarilis" se imprime dentro de La Filomena, lo que remite a una antigua gloria del Fénix. ${ }^{41}$

Pero entrelazado con la exaltación del poeta se halla el motivo de lo elevado, de lo celestial, y seguramente una atenta lectura de la sexta estrofa permitiría ver una cierta y amable burla de los intereses de Lope, bastante más terrenales. La misteriosa autora, sin embargo, también modula esa pureza celestial con la de-

41. Hay una referencia elogiosa a una amplia producción que no se especifica, pero la intención no es, dentro del tono dominante de la epístola-canción, establecer un catálogo de obras del poeta que es también prosista, sino dirigir la valiosa pluma de Lope hacia otros contenidos netamente espirituales. 
claración de un deseo que por limitado que aparezca queda muy teñido de erotismo: "Allá deseo en santo amor gozarte" (v. 109). "Gozarte" es forma verbal que puede estar muy connotada, al que hay que sumar el "deseo", y la propuesta, si bien podría ser aceptada como una exaltación monjil del amor espiritual, también puede ser una remisión más al carácter mixtificado del poema ${ }^{42}$ Basada en esa superioridad de lo celestial Amarilis propondrá con cuidado diversas correcciones a la obra del poeta, y consecuentemente a su vida, hasta culminar con el encargo final de que escriba la vida (otra vida, mucho más modélica) de una santa y abandone o limite, por tanto, otras formas de poesía. Creo que la primera corrección que propone en esa línea, inteligentemente engastada tras los enormes elogios, es esta:

\author{
Pues, peregrino mío, \\ vuelve a tu natural, póngante brío \\ no las murallas que ha hecho tu canto \\ en Tebas engañosas, \\ mas las eternas, que te importan tanto [...] \\ Las singulares gracias con que esmaltas \\ tus soberanas obras, \\ con que fama inmortal contino cobras, \\ empléalas de hoy más con versos lindos \\ en soberanos y divinos Pindos. \\ (vv. 104-108 y 115-119)
}

El largo poema cambia, tras la declaración de ese amor divinizado y tras el elogio, en uno de sus giros que podría haber querido imitar los de Horacio de haberse realizado con más fuerza, hacia una proyección supuestamente autobiográfica, y no menos horaciana, aunque la explicación no lo es, pues la confesión personal se vincula al conocimiento de quien declara su amor: "Quiero, pues, comenzar, a darte cuenta / de mis padres y patria y de mi estado, / porque sepas quién te ama y quién te escribe;" (vv. 127-129). La proyección es muy limitada y relativamente general. Un puñado de datos (unos abuelos conquistadores, padres nobles, educada por una tía una vez que se queda huérfana, una hermana casada y tan bella como Amarilis, su condición de religiosa) se sitúan en un Perú que carece de descripción o detalle. Más bien se busca un lenguaje poético y

42. En el comentario, estrofa por estrofa, de Vinatea Recoba (2009), solo se anota "allá" en este verso. La razón de trasladar el amor al cielo es doble y muy ajustada a la fama de Lope y al inflamado temperamento de la emisora: "pues acá es imposible poder verte, / y temo tus peligros y mis faltas" (vv. 110-111). Sin embargo "gozar" también puede tener un tono más neutro, como en la epístola cuarta, donde el "gozo" de los dos amigos se opone al "apetito" sexual: "Gozar se pueden dos entendimientos, / como agora yo a vos, que no os he visto, / y dar la voluntad sus pensamientos. / Mas como el apetito tan malquisto / de la razón, en femenil belleza, / que es lo que yo, platónico, resisto", Vega (Obras poéticas, p. 789, vv. 271-276). 
mitológico, con lo que la localización no parece precisar un conocimiento de primera mano de las tierras del exótico virreinato; solo se nombra la ciudad de León (v. 160) que sus abuelos fundaron (vv. 169 y ss.). ${ }^{43}$ La proyección biográfica tiene mucho de acertijo, con pistas repartidas en las estrofas, pero sin el suficiente calado como para que la crítica haya podido identificar a la autora:

De padres nobles dos hermanas fuimos, [...]

De la beldad que el cielo acá reparte nos cupo, según dicen, mucha parte, con otras muchas prendas.

(vv. 181 y $190-192)$

Lo más significativo del autorretrato es la insistencia en una pureza espiritual que, si bien sirve para subrayar la condición de una religiosa que respeta sus votos, parece buscar un contraste con la vida de su admirado destinario o constituirse incluso como provocación o, mucho más sutilmente, como una invitación para que Lope en su respuesta explique a su vez lo que parece imposible de defender:

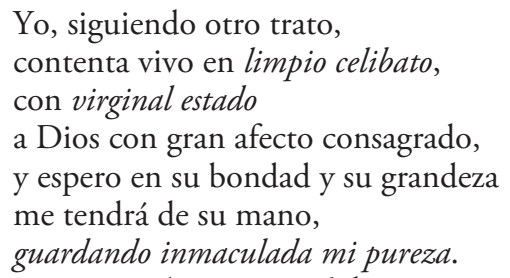

(vv. 210-216; la cursiva es mía)

Suena irónico que quien se ha enamorado de oídas (¿y qué ha oído de y sobre Lope?) insista con ahínco en una proclamación tan desnuda y orgullosa como "contenta vivo en limpio celibato" con la que implícitamente se resalta la enorme distancia, no geográfica en esta ocasión, sino moral con la vida de Lope, como si la epístola hubiera sido compuesta o alentada por un sibilino enemigo del Fénix, reforzada por la insistencia sexual de un "virginal estado" y una "inmaculada $[. .$.$] pureza”. No puede resultar más claro que Amarilis no será rival$

43. Aunque antes ha mencionado a Potosí y a Lima, ni siquiera se realiza ese esfuerzo, a menudo de segunda mano, de demostrar un amplio conocimiento, a diferencia de lo que el propio Lope hace en la quinta epístola de La Circe, cuando escribe a su amigo el doctor Martías de Porras al que pide noticias de "cómo os halláis en Lima, tierra extraña, / tan lejos ya de vuestro sol primero" y paradójicamente el propio poeta se explaya en comentarios geográficos y zoológicos antes de detenerse en que "mejor será cazar el oro y plata", Vega (Obras poéticas, pp. 1240-1241, vv. 173174 y 211). Sin duda, como indica Sobejano (1990: 19), "la visión de América que se dilata luego por numerosas estrofas no es sino una forma amistosa de ponerse con la imaginación en el lugar del compañero remoto". 
de una Celia (v. 228) no identificada. ${ }^{44}$ aunque lo irónico e hiriente es que Amarilis, que parece conocer las pasiones de su admirado destinatario así como sus derivaciones literarias, ${ }^{45}$ tan diferentes de su intensa proclamación de "pureza”, lo haga explícito.

Antes de que, cerca ya de la conclusión, la epístola-canción formule una petición cuando menos peculiar, el encargo de que Lope cante la vida de Santa Dorotea, pues es la santa que celebran Amarilis y su hermana, por un doble beneficio ("para bien de tu alma y mi consuelo", v. 281), el poema de detiene en los "dones" de la autora, que se concentran en la línea dominante del amor platónico: "un alma pura a tu valor rendida" (v. 254). El atrevimiento de la petición se justifica también de un modo menos concreto, pero en el subtexto sirve para subrayar esa diferencia de esta epístola que es una canción y que ha sido compuesta por una mujer: "ellos al fin son hombres y temieran, / mas la mujer, que es fuerte, / no teme alguna vez la misma muerte" (vv. 313-315).

La lectura del largo poema, si se atiende solo al sentido denotativo, permite concluir que una desconocida monja peruana cuenta en la epístola-canción quién es y canta su admiración por Lope en forma de casto amor (que se "gozaría" en el cielo), para terminar pidiéndole a su amado que cuente en verso la vida de santa Dorotea. ${ }^{46}$ También en la lectura es posible percibir una gran insistencia en lo celestial frente a lo terreno y, al mismo tiempo, una elevada exaltación de Lope. Cabe añadir que la canción con toques epistolares es, como casi todas las epístolas especialmente cuando se dirigen a un poeta, una invitación a una respuesta, y que si la autora cuenta su vida el destinatario estará obligado a contar la suya en la contestación; y si la autora se complace en su amor espiritual, el Fénix deberá corresponder, pero con la sinceridad que implica toda correspondencia epistolar; ${ }^{47} \mathrm{y}$ que, por último, el destinario deberá contestar la expresa y extraña petitio de que cante (quien ha sabido cantar a Angélica) a su santa preferida (que ella, a pesar de su pericia versificadora, no canta). Resulta, pues, imprescindible, atender a lo que

44. Un tanto oscura es la reflexión ¿̇maliciosa? sobre Celia: "Que ofendido en sus quiebras, / su nombre todavía al fin celebras, / y aunque milagros su firmeza haga, / te son muy bien debidos, / y aun no sé si con esto tu fe paga" (vv. 230-234). Toda la estrofa siguiente plantea, al final, la dificultad de Amarilis para entender los amores más físicos, aunque previamente se ha detenido en la imposibilidad de la competencia entre ambas, física ("que trópicos y zonas nos dividen”, v. 236) y moral. En su respuesta Lope se muestra esquivo y usa el plural para referirse a las "Celias" tanto del cielo como de la tierra (vv. 259-261), lo que parece eludir cualquier identificación.

45. "De trenzas de oro, cejas, y ojos bellos, / cuando enredado te hallaste en ellos, / bien supiste estimallos, / y en ese mundo y en este celebrallos; / y en persona de Angélica pintaste" (vv. 240-244). 46. Es todo un atrevimiento realizar un encargo literario, pues previamente ha reconocido que la trayectoria literaria del poeta está en su cénit: "He querido, pues, viéndote en la cima / del alcázar de Apolo, / como su propio dueño único y solo" (vv. 277-279).

47. Lope así lo entiende en su respuesta y se apresura a trazar un claro límite en su relato autobiográfico: "Deciros faltas es desconfianza, / y porque yo jamás las dije ajenas, / no quiero hacer en mí tan gran mudanza: / que no era gala de quien sirve apenas / pintarse con defetos a quien tiene / aquellas obras cuales son por buenas" (vv. 52-57). 
Lope revela en su contestación sobre el sentido de esa híbrida epístola, tan insólita en su métrica y en su alejamiento de la convención horaciana y, por último, en su petición que obliga al Fénix a corresponder con el recuento de su vida a los casi sesenta años. Sin embargo no deja de resultar curioso que buena parte de los estudios que pretenden elucidar la identidad de la misteriosa Amarilis no solo hayan evitado analizar la epístola de "Amarilis a Belardo", como ya se constataba hace más de siete décadas, ${ }^{48}$ sino también la respuesta de Lope. Quizá ahora el pretexto es que Amarilis es indiana y Lope castellano, o, dicho de otro modo, que la epístola de Amarilis es una joya de la literatura virreinal o colonial, pero la de Lope forma parte del acervo español o peninsular, en una cómoda e insatisfactoria división. Junto a las pistas, muy abiertas como se ha visto, que desgrana Amarilis es imprescindible atender a la respuesta de Lope, quien, además, es el editor, con sus criterios e intenciones, del misterioso poema.

\section{Sospechas en una respuesta: "y la misma alabanza desengaños"}

La detención de Lope en su vida parece un lugar recurrente a la altura de 1621, cuando ya ha disfrutado de la animadversión expresa de sus enemigos y eso podría explicar que en su respuesta a Amarilis cuente su vida como una autodefensa, al corresponder a las confidencias de su admiradora, y, por más que la vida de Amarilis no se remanse en detalles de verdad sustanciosos, Lope aprovecha el insólito poema más que para un descargo de conciencia para que la cuidada defensa pro vita sua tenga una justificación. Y por eso la respuesta de Lope está muy lejos de su famosa explicación a Juan de Arguijo, en la epístola nona de La Filomena, sobre el desorden estructural del género: su respuesta sigue el ordenado cauce que ha marcado Amarilis y no tiene nada de "centón", ni de "capítulo" e incumple clamorosamente aquello que señalaba a la epístola como el texto "donde apenas se engarzan las razones". ${ }^{49}$ No me cabe duda de que en gran parte ese es el rol reservado a la colocación central de la epístola de la supuesta peruana, servir de indiscutible apoyo estructural a la parte del león de la epístola de Lope, los casi doscientos versos en los que el Fénix repasa los highlights de su compleja vida. No hay que descartar que el poema de Amarilis parta de una burla de enemigos que quieren buscarle las vueltas a un poeta narcisista al que colman de elogios ("No Belardo, milagro han de llamarte", v. 56) y al que al mismo tiempo quieren arrinconar o comprometer. En esa línea se puede interpretar el rechazo directo de Lope a la invitación de escribir la vida de Santa Dorotea.

48. "La crítica ha solido perseguir el esclarecimiento del problema histórico referente a la personalidad de Amarilis; pero el análisis de su "Epístola" ha quedado reducido al elogio o a la glosa", Tauro (1945: 45).

49. Vega (Obras poéticas, p. 850, vv. 253-255). 
La respuesta de Lope no solo goza de una sólida autoría sino que es una epístola canónica desde su propia forma en tercetos encadenados..$^{50}$ Algo más breve, con doscientos ochenta versos, la epístola no se caracteriza por hibridismos con otros géneros, lo que la coloca a la altura de las otras siete epístolas del Fénix de $\mathrm{La}$ Filomena y de la epístola de Baltasar Elisio de Medinilla, aunque el largo y estratégico relato de la vida del poeta la sitúa, no formalmente pero sí por el contenido, en otro rango. Estructuralmente aparecen seguidas, unidas, la canción-epístola de Amarilis y la respuesta del Fénix, para crear un efecto desde esa dispositio, un efecto muy distinto del que se persigue con la separación de la epístola de Baltasar Elisio de Medinilla y la epístola de este a Lope, que no es una respuesta. ${ }^{51}$

La epístola séptima: ${ }^{52}$ se inicia con una broma, signo inequívoco del buen humor del Lope y nota muy propia de la epístola horaciana: "Agora creo y en razón lo fundo, / Amarilis indiana, que estoy muerto, / pues que vos me escribís del otro mundo" (vv. 1-3). El humor es rasgo horaciano, y aunque los juegos suelen reservarse para el interior del texto y mucho más si se trata de una pieza de cierta extensión, como la presente, América parece exigir esta broma estereotipada. ${ }^{53}$ Tampoco es irrelevante que Lope distinga de forma inmediata a esa Amarilis, "indiana", de la Amarilis más conocida. ${ }^{54}$ Es cierto que la maestría de Lope le permite manejar con mucha soltura los tópicos de la comunicación epistolar, aunque aquí las bromas se acumulan en el comienzo, a veces con un toque ácido que se disfraza de una seriedad fingida como cuando reconoce que "bien sé que en responder crédito empeño" (v. 10), en una época de su vida donde ya lo ha ganado casi todo; otras, entregado a las artes del elogio, pues ya sabe que los ingenios indianos son especiales: "mas los que el clima antártico produce / sutiles son, notables son en todo" (vv. 19-20).

Es fácil percibir, también desde el mismo comienzo, una cautela que atraviesa la composición. Así Lope recoge el guante de un lejano amor de oídas, muy halagador, pero se queja con amabilidad: "En mares tan remotos y diversos, / ¿cómo podré yo veros, ni escribiros / mis sucesos, o prósperos o adversos?" (vv. 25-27; la cursiva es mía). La lejanía en este caso es un tema obligado, pero la

50. Para el detalle de las alusiones biógraficas conviene acudir a la anotación de Carreño (Lope de Vega, Rimas humanas y otros versos, pp. 658-668 y 1053-1056).

51. Calvo (2020).

52. Guillén (1995: 169, 171-173) clasifica en cinco grupos las epístolas de Lope e incluye la respuesta a Amarilis en el primero (porque se dirige a una desconocida): las de "carácter ficticio o novelado" (que es "más fácilmente coherente y homogénea que otras"), las panegíricas, la "satírico-literaria", filosóficas y las "predominantemente morales" (que son, junto con las primeras, "las mejores”). Sobre la relación de epístola y novela véase Díez (1993).

53. En la epístola "Al doctor Matías de Porras, corregidor y justicia mayor de la provincia de Canta en el Pirú", la quinta de La Circe, el doloroso recuerdo de su hijo Carlos lo inicia Lope, sin embargo, con la obligada broma: "Después, señor doctor, que me dejastes, / y sin morir al otro mundo os fuistes”, Vega (Obras poéticas, p. 1234, vv. 1-2).

54. Vega (Cartas sobre Amarilis). 
insistencia en ella puede ser también indicio de incredulidad o incluso una irónica respuesta a lo que se percibe como una broma o, al menos, se interpreta con distancia, con otro tipo de distancia. Lope, desde luego, no deja de contestar muy finamente al ofrecimiento amoroso y ańade algo que puede estar cargado de intención: "Amo naturalmente a quien me ama / y no sé aborrecer quien me aborrece: / que a la naturaleza el odio infama” (vv. 31-33).

Tras cumplir con la retórica educada y receptiva del introito, Lope sabe que debe hablar de sí mismo, que tiene que recoger el guante de la confesión, que es una obligación de esa poética del yo que viene a imponer el género epistolar horaciano, pero lo hace desde una tonalidad característica de un discurso que deberá ir creciendo en otras direcciones para componer una extensísima defensa pro vita sua: "Mas ¿qué os diré de mí? Porque no siento / que un átomo merezca de alabanza / quien tiene presunción de su talento" (vv. 49-51). Lope renuncia a hablar de sus defectos, pero dirá la verdad, al menos una parte y antes de que comience su largo relato, el núcleo de la respuesta, confesará corresponder al amor ("que dejaros de amar injuria fuera", v. 62). Su autodefensa es algo más que una mera correspondencia por correspondencia. ${ }^{55}$ No se ahorran los elementos amables y simpáticos ("En fin, por celos soy, ¡qué nacimiento!", v. 85), pero sobre todo Lope sabe perfectamente que su poesía refleja su vida, quizá como en ningún otro poeta, lo que hace innecesaria la explicación: "Lo demás preguntad a mi poesía: / que ella os dirá, si bien tan mal impresa, / de lo que me ayudé cuando escribía" (vv. 115-117). Remitir a la lectura de su poesía a quien solo conoce $L a$ hermosura de Angélica es una respuesta un tanto desabrida. Decía antes que la poética epistolar, y la horaciana no es una excepción, obliga a un planteamiento sincero, con todo lo que ese adjetivo conlleva cuando se trata de literatura. Quizá de modo más realista hay que valorar, dentro de la selección de los hechos que componen una larga vida, un planteamiento que incluya no solo esos hechos sino también pensamientos y emociones. Así Lope se entrega a esa exhibición sentimental cuando trata de su hijo Carlos, ${ }^{56}$ habla de todos sus hijos y no evita el espinoso asunto de su condición sacerdotal, aunque se vale de un juego de palabras que fundamenta la raíz defensiva de este relato autobiográfico: "ordenéme, Amarilis; que importaba / el ordenarme a la desorden mía” (vv. 155-156).

55. "Si la inclusión de la epístola [de Amarilis] por parte de Lope en este lugar tiene que ver con una opción estructural, la epístola funciona como un envión para la respuesta en la que Lope cuenta su vida privada en un ámbito de intercambios masculinos y literarios. Pero entiendo que, por ahora, no podemos pensar este intercambio como un lugar en el que se cruza la estructura con el contexto", Calvo (2020: 158). Creo, sin embargo, que podemos y debemos pensarlo, y así lo demuestra el más reciente trabajo de Campana (2021), que solo he podido consultar una vez enviado mi estudio.

56. "Un hijo tuve, en quien mi alma estaba; / allá también sabréis por mi elegía / que Carlos de mis ojos se llamaba [...] / ¡Cuánto fuera mejor que yo muriera / que no que en los principios de su aurora / Carlos tan larga noche padeciera" (vv. 121-123 y 133-135). La referencia a una obra concreta por parte de Lope ¿ilumina a esta destinataria que solo puede citar dos obras del Fénix? 
La respuesta de Lope es brillante y por eso al tiempo que rechaza que todos sus versos de amor sean biográficos destruye una imagen de seductor que aún le persigue, en unos versos cuyo alcance puede llegar a poner en cuestión también el texto que firma Amarilis con su defensa del oído como el medio para acercarse al Fénix. Es también, de un modo extraordinariamente revelador, prueba de cómo Lope entiende que un poema de lejano y misterioso origen tiene una base en las habladurías (con otro sentido muy distinto de la lectura y la fama como fuentes de la información de la también borrosa Amarilis): ${ }^{57}$ "Quien piensa que yo amé cuanto miraba, / vanamente juzgó por el oído; / engaño que aun apenas hoy se acaba" (vv. 157-159; la cursiva es mía). Lope también se queja de su juventud y de que sus versos no sean oscuros como los de otros, pues es mucho más fácil interpretar la poética de la claridad, aunque con mucha insistencia en el oído, el sentido por excelencia que cultiva Amarilis. El poeta así se defiende doblemente: critica a los gongorinos y su moda en un comentario de alcance metapoético y arroja sutilmente dudas sobre las interpretaciones de Amarilis para, a partir del alma como concepto básico de la epístola-canción de la supuesta peruana-y de nuevo de manera muy hábil—, no solo contraponer la diferente valoración de lo realmente vivido, sino para, en una defensa muy bien trabada, volver al razonamiento antártico y asegurarle a su destinataria, con esta ingeniosa finta, que él también la ama y sin peligro alguno:

Los claros pensamientos que perciben sin molestia, Amarilis, los oídos, menos seguros de ser castos viven. Tiernos concetos del amor nacidos no son para la vida imperfecciones, ni está sujeta el alma a los sentidos [...] No pienso que a la vida parte alcanza, juzgando bien de la amorosa pluma, si el alma es posesión, la fe esperanza [...] Y así podréis amarme justamente, como yo os amo, pues las almas vuelan $\tan$ ligeras, que no hay amor ausente. (vv. 166-171, 175-177 y 181-183)

Todo el argumento que desarrolla el Fénix se apoya en la insistencia de Amarilis en el alma, ${ }^{58}$ cuyo efecto Lope ha calificado con acierto como de amor plató-

57. "Por varios mares, por distintos cielos / muchas cosas se dicen que no tienen / tanta verdad al descubrir los velos" (vv. 256-258).

58. Lope entiende muy bien el sentido de la "Epístola de Amarilis", desde la misma importancia del alma, cuando acusa recibo del envío: "pues, desde el mar del Sur, nave de pluma / en las puertas del alma toma puerto" (vv. 5-6). Y luego lo reitera, con mucho humor ("Del alma que os adora sé deciros / que es gran tercera la divina fama; / por imposible me costáis suspiros”, vv. 2830) o con la seriedad del que quiere compartir las ideas de su interlocutora ("que adonde amor es 
nico (v. 59). Y tras el resumen de los hechos que tejen esta bien armada autodefensa, la epístola describe y valora la vida actual del poeta para remitir de nuevo a la literatura como el centro de su vida, contada o vivida: "Mi vida son mis libros, mis acciones / una humildad contenta, que no envidia / las riquezas de ajenas posesiones" (vv. 193-195). Aunque los libros son también un conocido tópico de la epístola horaciana, así como el rechazo de la vida cortesana con sus ambiciones, Lope tiñe con toques personales su rechazo de esa persecución horacianamente absurda (con mención de Séneca) y se adentra en el elogio del verdadero sabio, con otro giro tan horaciano como los anteriores: los tres absolutamente ausentes de la epístola de Amarilis: "Estimo la amistad sincera y pura / de aquellos virtuosos que son sabios: / que sin virtud no hay amistad segura" (vv. 220-222).

Responde así Lope al desmesurado elogio de Amarilis pero todo se impregna además de una buscada ambigüedad que podría responder a una duda sobre la procedencia real de la epistola $\mathrm{o}$, mucho más simplemente, porque el poema de Amarilis es una invitación callada al resumen confesional. La sinceridad se valora expresamente tanto para dar calor a unas palabras que piden ser consideradas muy personales pero también se exalta lo excepcional de esta situación: "De mi vida, Amarilis, os he escrito / lo que nunca pensé; mirad si os quiero, / pues tantas libertades me permito" (vv. 226-228). El elogio de este amor es largo, un amor de pensamiento y sin ojos, que le permite llegar a las Celias, con un giro de ingenio para subvertir la dualidad cielo/suelo con un intento de elevación muy logrado: 59 "Celias de solo el cielo me entretienen; / no las temáis, que Celias de la tierra / a ser infiernos de las almas vienen” (vv. 259-261).

La respuesta de Lope al encargo de escribir poesía religiosa creo que sin duda refuerza la idea de que ha entendido muy bien o la broma o el carácter excipiente de esa petición y ha decidido contestar, dentro del juego de la epístola, para exhibir una autodefensa que sus posibles enemigos sentirán como una decepción: "cantad su vida vos, pues que se emplea / virgen sujeto en casto pensamiento, / para que el mundo sus grandezas vea” (vv. 268-270). Y algo más, pues Lope no solo devuelve el encargo sino que también propone una tarea a la poetisa invitándole a componer un poema épico sobre sus "padres" y con eso

alma, el cuerpo es sombra, / y la misma alabanza desengaños”, v. 68-69). Y es que Amarilis desde el inicio de su canción-epístola construye su declaración amorosa a partir del alma y del rechazo de lo corporal ("al alma tiernamente aficionarla", v. 3) hasta la misma conclusión: "guiad un alma que sin alas vuela” (v. 335). Sin embargo esa línea continua no evita lo acerado de esta peculiar pasión ("y así quiero hacer una reseña / de amor dificultoso, / que, sin pensar, desvela mi reposo, / amando a quien no veo y me lastima”, vv. 31-34).

59. “¡Oh, cuánto acertarás si imaginares / que es patria tuya el cielo / y que eres peregrino acá en el suelo! / Porque no hallo en él quien igualarte / pueda, no solo en todo, mas ni en parte, / que eres único y solo / en cuanto miran uno y otro polo", escribe Amarilis (vv. 97-103), muy lejos de la visión del propio Lope de la primera epístola ("A don Francisco de la Cueva y Silva, insigne jurisconsulto"): "Soy en secreto a muchos arquetipo, / que en público me niegan, mas no importa, / así de Marte y Venus participo”, Vega (Obras poéticas, p. 754, vv. 136-139). 
concluye su epístola, con una suerte de enmienda a la totalidad, con un aire de fresca suspicacia hacia una monja tan espiritual, tan lejana del cuerpo, tan sutilmente perversa, que no sabe o no quiere ver que tiene un material de primera mano para desarrollar en su poesía, o al menos el tema es el que parece interesar más a Lope, que entiende como nadie, y quizá con sus puntas de sospecha, el valor de una poesía heroica y guerrera al servicio del rey:

Honrad la patria vuestra propagando
de tan heroicos padres la memoria,
su valor generoso eternizando,
pues lo que con la espada su vitoria
ganó a su sangre, vos, en dulce suma,
coronando laurel de mayor gloria,
dos mundos de Filipe vuestra pluma. (vv. 274-280)

La indudable ordenación de las diez epístolas de La Filomena permite percibir el cuidado con el que Lope ha dispuesto las epístolas sexta y séptima. Con independencia de la fecha de composición de todas ellas ${ }^{60}$ Lope las publica y las numera de acuerdo con sus intereses. Parece claro por qué reserva un lugar central a la de Amarilis y también cómo prepara el exotismo de la aparente composición peruana en las dos epístolas anteriores, tan distintas. En la cuarta, la última de todas por su redacción, Lope bromea para su destinatario sevillano sobre lo fácil que sería detener el Manzanares en comparación con el Guadalquivir, con la evidente intención de oponer la cosmopolita Sevilla y la corte. El contacto de América es con Sevilla y no con Madrid, sin embargo la sorpresa de la epístola sexta refuerza el elogio del Fénix con este texto que milagrosamente sí ha llegado a la ciudad del Manzanares, ${ }^{61}$ pues la fama de su destinario no cono-

60. Sobejano (1993: 23) supone un iter compositivo que va desde 1611 (para la epístola novena, a Juan de Arguijo) hasta 1621 (para la epístola cuarta, a Diego Féliz Quijada y Riquelme), pero, como es obvio, la epístola de Amarilis, que no es de Lope, no está fechada. Otras precisiones sobre las posibles dataciones en Sobejano (1990: 18). Sobre el cuidado organizativo de La Filomena y La Circe véase Campana (2000), que se ocupa de otros aspectos generales y no de las epístolas, y Campana (2021).

61. Y Lope no olvida que Amarilis, con el juego del término "peregrino" en relación con la novela del Fénix, pero también como fórmula para exaltar a su alma gemela, le propone aumentar su gloria con permiso de lo terrenal, representado por el Manzanares y con toda su pequeñez, característica de tantos chistes de los Siglos de Oro, pero que aquí entra en correlación con el Nuevo Mundo: "En tu patria, Belardo (mas no es tuya), / no sientas mucho verte peregrino / (plegue a Dios no se enoje Manzanares), / por más que haga de tu fama suya, / que otro origen tuviste más divino, / y otra gloria mayor si la buscares" (vv. 91-96). La epístola cuarta concluye con una expresiva superación: "así se rinde al Betis Manzanares", Vega (Obras poéticas, p. 790, v. 295). Y en la quinta epístola de La Circe también se vale del Manzanares para oponerlo a América: "volver un hombre pobre a Manzanares, / sino traer el nuevo mundo a cuestas / y descansar entre los patrios lares”, Vega (Obras poéticas, p. 1242, vv. 232-234). 
ce fronteras. En la quinta epístola, toda elogios hacia el conde Lemos y que puede parecer poco integrada en la colección, incluye numerosas referencias a América, a México en concreto, que se justifican por ser el de Lemos presidente del Consejo de Indias. Lope, sin haber puesto un pie allí, traza una colorista descripción donde aparecen la laguna, "las frutas de color y hechura extraña", "las aves de más visos y labores" e incluso un grupo "de hombres desnudos con sus flechas y sus arcos". ${ }^{62}$ El lector percibe ese deslizamiento sutil desde el elogio del alto señor por Lope y el del propio Lope a manos de una poetisa que se dice peruana. Por otro lado en su respuesta a Amarilis Lope marca también un contraste al recoger la limitada geografía de su vida. Y en la epístola octava, dirigida a "Al licenciado Francisco de Rioja, en Sevilla", Lope vuelve a recuperar la amplitud de "la gran ciudad por quien discurre a Tetis / mayor que la que dio, famosa, a Nino / la hija del gran ídolo Dercetis" (vv. 10-12), muy dentro de los tópicos de los Siglos de Oro pero que tienen aquí una utilidad evidente, señalada desde la propia localización en la dedicatoria. Frente a la grandeza de la ciudad y el destinatario Lope tratará de su jardín y así se titula el poema: "El jardín de Lope de Vega", con una broma que solo se hace explícita al final de la epístola. No puedo aquí sino apuntar que también el neoplatonismo del que hacen gala tanto Amarilis como Lope ${ }^{63}$ viene preparado desde la cuarta epístola.

\section{Hibridismo y autodefensa}

El hibridismo de la canción-epístola de Amarilis, un poema que está muy lejos de la poética horaciana, es aprovechado por Lope ${ }^{64}$ para componer en su respuesta y por contraste una epístola muy horaciana, aunque no vaya formalmente destinada a un hombre. En ella no solo cumple las obligaciones de toda respuesta a una epístola previa, sino que sobre todo se apoya en la sucinta proyección biográfica de Amarilis para componer un denso y unitario cuerpo de su epístola (en los versos 50 a 225) que se centre en una visión favorable de su propia vida.

62. Vega (Obras poéticas, pp. 793-794, vv. 101, 106 y 113).

63. Dentro de la autodefensa de sus amores se puede encuadrar el intento de "dignificar y justificar con lo platónico" (Blecua 1969: 561) su relación con Marta de Nevares. Por otro lado, el impulso autodefensivo es el que justifica la publicación de La Filomena ("la constante autodefensa del autor, unida al ataque mesurado contra sus detractores, es uno de los criterios unificadores del conjunto, la estructura subyacente y profunda de toda la obra”, Campana 2000: 429) y en él se insertan admirablemente y con características muy propias las dos epístolas, la de Amarilis y la respuesta de Belardo.

64. Cuando ya se había enviado este trabajo me llega el último estudio de Vinatea Recoba (2021), en el que valora como una defensa la epístola de Amarilis. Creo, sin embargo, que es mucho más preciso considerar que Lope reaprovecha el poema para componer su autodefensa, y lo hace, como he explicado, por su estudiada dispositio en la colección epistolar y, sobre todo, por su uso como la excusa que da pie a la respuesta de Belardo. 
El sentido del humor es tan horaciano como característico de Lope. Hay una breve reflexión filosófica con sus referencias estoicas, aunque el rechazo de los elementos de pureza espiritual en los que tanto insiste Amarilis se concentra en la brusca y muy explícita negativa de orientar su poesía hacia las vidas de santos, en un auténtico revés de maestro. Lope se vale así de una canción-epístola, con su señalada hibridación como pista señera, para componer un texto canónico con el que, desde su adecuación rigurosa al género que parece despreciar o desconocer la misteriosa Amarilis, reforzar una afirmación personal a través de una vida sólida y segura. Aquí la forma se suelda con el contenido para dar una respuesta yo diría que rocosa a la destinataria, que las cortesías y el buen humor solo maquillan para que encaje dentro de la más aceptada práctica epistolar. ${ }^{65}$

Con independencia de quién haya compuesto la epístola que firma Amarilis, Lope de Vega se vale de su hibridismo para ordenar su colección de epístolas en $L a$ Filomena de un modo utilitario y favorable. Las peticiones, las alabanzas y un amor platónico (que es una forma más de elogio), además de una mínima proyección o confesión biográfica son reconvertidas por el Fénix en su respuesta en una demostración de poder autodefensivo que borra o al menos explica las tachas que sus enemigos se complacen en airear para convertir una respuesta a una supuesta admiradora peruana en una epístola en la que el emisor brille aún con una luz más propia. Incluso el contraste marcadísimo con una epístola que se vale de una métrica inusual, la propia de la canción, queda hábilmente realzado tanto por su colocación (en el centro de las diez epístolas) como por su evidente contraste con las otras nueve muestras del arte epistolar, incluyendo una que no es de Lope. El cálculo, tanto en la composición de la epístola en estancias como de su cuidada dispositio, fija la atención del lector en un texto insólito en la colección que por sí mismo supone una exaltación del poeta, en boca o en la pluma nada menos que de una mujer, monja (y hay que pensar que a salvo de sospechas de un erotismo carnal) e indiana (y por ello alejada del ruido de la Corte, tan halagador en parte y tan molesto en otra). Si el lector completa la información, como es deseable, con la respuesta del Fénix el balance extraordinariamente positivo del retrato y el autorretrato de un escritor más que curtido en las artes literarias (y que incluyen esa autopropaganda con diversos fines, en un libro de por sí concebido para esa interpretación favorable que comienza por la visión personal del mito de Filomena que titula la colección), el efecto es multiplicador. Por eso, aunque no haya una prueba que pueda resultar definitiva, cabe sospechar con las presunciones desarrolladas que el poema de Amarilis es una auténtica forgery, aunque lo más importante es el uso o el aprovechamiento brillante de Lope para proyectar un significado inequívoco en beneficio muy propio.

65. Estévez Molinero (2000: 308) señala "las heroidas dobles" como "posible modelo" con rasgos horacianos en la respuesta, pero creo que el juego es otro y Lope corta a su medida una relación epistolar con un más que probable pie forzado, de encargo o reaprovechado para esa función. 


\section{Bibliografía}

Aladro, Jordi, y Ricardo Ramos-Tremolada, "La epistola de Amarilis a Belardo, una misiva del Perú mestizo a España", Hipogrifo, III, 1 (2015), pp. 69-87.

"Amarilis Huánuco Perú", en línea, <http://www.webhuanuco.com/amarilis. htm> [consulta del 29 de diciembre de 2020].

Arellano, Ignacio, y Carlos Mata, Vida y obra de Lope de Vega, Madrid, Homo legens, 2011.

Becco, Horacio Jorge (ed.), Poesía colonial hispanoamericana, Caracas, Ayacucho, 1990.

Blecua, José Manuel (ed.), Lope de Vega, Obras poéticas, Barcelona, Planeta, 1969.

Calvo, Florencia, "Lope y Baltasar Elisio de Medinilla: sus epístolas en la estructura de La Filomena", Atalanta, VIII, 2 (2020), pp. 147-160.

Campana, Patrizia, "La polémica epístola 'Amarilis a Belardo", Anuario Lope de Vega, III (1997), pp. 7-24.

—, "La Filomena de Lope de Vega como género literario", en Actas del XIII Congreso de la Asociación Internacional de Hispanistas: Madrid 6-11 de julio de 1998, I, Medieval. Siglos de Oro, ed. Florencio Sevilla Arroyo y Carlos Alvar Ezquerra, Madrid, Castalia, 2000, pp. 425-432.

-, "Las epístolas de La Filomena de Lope de Vega como macrotexto", Arte Nuevo, Revista de Esudios Aureos, VIII (2021), pp. 24-46.

Castro, Américo, y Hugo A. Rennert, Vida de Lope de Vega (1562-1635), Madrid, Anaya, 1968.

Chang-Rodríguez, Raquel (ed.), Clarinda y Amarilis, discurso en loor de la poesía. Epistola a Belardo, Lima, Universidad Católica del Perú, 2009.

Díez, J. Ignacio, "Marcos de Obregón en tres epístolas de Vicente Espinel”, Dicenda. Cuadernos de Filología Hispánica, XI (1993), pp. 71-111.

—, "Notas sobre la carta en octosílabo", en La epistola. V Encuentros sobre Poesía Española del Siglo de Oro, ed. Begoña López Bueno, Sevilla-Córdoba, Universidad, 2000, pp. 151-180.

—, "Las epístolas de Barahona de Soto en el sistema epistolar de los Siglos de Oro", en De saber poético y verso peregrino. La invención manierista en Luis Barahona de Soto, ed. José Lara Garrido, Málaga, Universidad, 2002a, pp. 163-188.

—, "La diversidad epistolar en la poesía de don Diego Hurtado de Mendoza", Canente: revista literaria, núm. 3-4 (2002b), pp. 149-176; reimp. en La epistola poética del Renacimiento español. Anejo LXXIII de Analecta Malacitana, coord. José Lara Garrido, Málaga, Universidad, 2009, pp. 145-171.

—, "La "Epístola satírica y censoria": un memorial reaccionario ... y moderno", La Perinola. Revista de investigación quevediana, XII (2008), pp. 33-53.

Estévez Molinero, Ángel, "Epístolas en clave ficticia de Lope de Vega: a propósito del género y de la literariedad", en La epistola. V Encuentros sobre 
Poesía Española del Siglo de Oro, ed. Begoña López Bueno, Sevilla-Córdoba, Universidad, 2000, pp. 295-309.

Fosalba, Eugenia, "La epistolaridad", en Pulchra Parthenope. Hacia la faceta napolitana de la poesía de Garcilaso, Madrid-Fráncfort del Meno, Iberoamericana-Vervuert, 2019, pp. 81-123.

Goyri, María, "La Celia de Lope de Vega", en De Lope de Vega y del romancero, Zaragoza, Librería General, 1953, pp. 103-174.

Guillén, Claudio, "Sátira y poética en Garcilaso", en Homenaje a Casalduero, Madrid, Gredos, 1972, pp. 209-232.

—, "Las epístolas de Lope de Vega", Edad de Oro, XIV (1995), pp. 161-167.

Holloway, Anne, "Sujetos periféricos, diálogos parnasianos: la voz femenina y la epístola en la poesía colonial”, en Los géneros poéticos del Siglo de Oro: centros y periferias, ed. Rodrigo Cacho Casal y Anne Holloway, Londres, Tamesis, 2013, pp. 233-252.

Lohmann Villena, Guillermo, Amarilis indiana: identificación y semblanza, Lima, Universidad Católica del Perú, 1993.

López GrÉGoris, Rosario, "Las fuentes clásicas y el imaginario poético femenino en la Epistola a Belardo de Amarilis y en el Discurso en loor de la poesía de Clarinda", Revista de estudios latinos, IX (2009), pp. 191-205.

Marías, Clara, Conversaciones en verso. La epistola ética del Renacimiento y la construcción del yo poético, Berlín, Peter Lang, 2020.

Mayne-Nicholls Verdi, Alida, "Amarilis y Delia Domínguez: nexos entre dos poetas desde la conciencia de ser mujeres-autoras", Literatura y lingüistica, núm. 27 (2013), pp. 33-44.

Millé y Jiménez, Juan, "Lope de Vega y la supuesta poetisa Amarilis", Revista de Archivos, Bibliotecas y Museos, VII (1930), pp. 1-11.

Montesinos, José F. (ed.), Lope de Vega, Poesias líricas. II. Canciones. Epistolas. Romances. Poemas diversos [1926], Madrid, Espasa-Calpe, 1973.

Ortiz SÁnchez, María de Lourdes, "Amarilis a Belardo: epístola de una escritora novohispana a un autor peninsular", Cuadernos del Hipogrifo. Revista de Literatura Hispanoamericana y Comparada, núm. 8 (2017), pp. 157-168.

Ponce Cárdenas, Jesús, “Delicaturas' y 'modos nuevos' de la poesía renacentista: las epístolas de Gutierre de Cetina”, Canente: revista literaria, núm. 3-4 (2002), pp. 177-216.

Rivers, Elias L., "The Horatian Epistle and its Introduction into Spanish Literature", Hispanic Review, XXII (1954), pp. 175-194.

—, "La epístola en verso del Siglo de Oro", Draco, núm. 5-6 (1993-1994), pp. 13-31.

Rozas, Juan Manuel, "El género y el significado de la Égloga a Claudio de Lope de Vega”, en Serta philologica F. Lázaro Carreter, Madrid, Cátedra, 1983, pp. 465-484; reimp. en Estudios sobre Lope de Vega, ed. Jesús Cañas Murillo, Madrid, Cátedra, 1990, pp. 169-196.

Sabat de Rivers, Georgina, "La epístola a Amarilis y su amor por Lope; ver, oír”, Hispanic Review, LVIII, 4 (1990), pp. 455-467. 
SÁnchez Jiménez, Antonio, Lope: el verso y la vida, Madrid, Cátedra, 2018.

Sánchez Robayna, Andrés, "Los tercetos gongorinos de 1609 como epístola moral”, en Silva gongorina, Madrid, Cátedra, 1993, pp. 83-99.

Serna, Mercedes (ed.), Poesía colonial hispanoamericana (siglos XVI y XVII), Madrid, Cátedra, 2004.

Sobejano, Gonzalo, "Confianza y literatura: las epístolas poéticas de Lope de Vega", Insula, revista de letras y ciencias humanas, núm. 520 (1990), pp. 17-20.

—, "Lope de Vega y la epístola poética", en Estado actual de los estudios sobre Siglo de Oro. Actas del II Congreso Internacional de Hispanistas del Siglo de Oro, ed. Manuel García Martín et al, Salamanca, Universidad, 1993, I, pp. 17-36.

Tauro, Alberto, Amarilis indiana, Lima, Ediciones Palabra, 1945.

VegA, Lope de, Cartas sobre Amarilis, último amor, pról. Rafael Alberti, Buenos Aires, Bajel, 1944.

—, Laurel de Apolo, ed. Antonio Carreño, Madrid, Cátedra, 2007.

—, Obras poéticas, ed. José Manuel Blecua, Barcelona, Planeta, 1969.

-, Poesías líricas. II. Canciones. Epistolas. Romances. Poemas diversos, ed. José F. Montesinos [1926], Madrid, Espasa-Calpe, 1973.

—, Rimas humanas y otros versos, ed. Antonio Carreño, Barcelona, Crítica, 1998.

Vinatea Recoba, Martina (ed.), Epistola de Amarilis a Belardo, Madrid, Universidad de Navarra-Iberoamericana-Vervuert, 2009.

—, "Amarilis, "primicia" del imperio español y la línea equinoccial, sirena", Bulletin Hispanique, CXIX, 1 (2017), pp. 299-314.

—, "'Con gran razón, a tu valor inmenso, consagran mil deidades sus labores'. La Epistola de Amarilis a Belardo como defensa de la obra de Lope de Vega", Janus: Estudios sobre el Siglo de Oro, núm. 10 (2021), pp. 151-168. 
